\title{
Novos táxons em Galerucini e redescrição de Caraguata circumcincta Clark (Coleoptera, Chrysomelidae, Galerucinae)
}

\author{
Luciano de A. Moura
}

Museu de Ciências Naturais, Fundação Zoobotânica do Rio Grande do Sul. Caixa Postal 1188, 90001-970 Porto Alegre, Rio Grande do Sul, Brasil. Bolsista CNPq. E-mail: Imoura@cpovo.net

\begin{abstract}
New taxa on Galerucini and redescription of Caraguata circumcincta Clark (Coleoptera, Chrysomelidae, Galerucinae). New species from Brazil are described and illustrated: Cornubrotica iuba sp. nov. (Bahia) and Zischkaita caapura sp. nov. (Amazonas). Redescription of Caraguata circumcincta (Clark, 1865), here illustrated for the first time, includes new morphological characters as male and female genitalia, and external characters not employed until now.
\end{abstract}

KEY WORDS. Galerucina, Luperina, Neotropical, new species, taxonomy.

RESUMO. Novas espécies do Brasil são descritas e ilustradas: Cornubrotica iuba sp. nov. (Bahia) e Zischkaita caapura sp. nov. (Amazonas). A redescrição de Caraguata circumcincta (Clark, 1865), ilustrada pela primeira vez, inclui novos caracteres morfológicos como a genitália masculina e feminina e caracteres externos não utilizados até o momento. PALAVRAS CHAVE. Galerucina, Luperina, Neotropical, novas espécies, taxonomia.

Entre os representantes neotropicais da Subtribo Luperina com garras tarsais bífidas, os gêneros que apresentam espécies em que os machos possuem antenas com os antenômeros apicais dilatados, escavados e glabros ventralmente estão Anisobrotica Bechyné \& Bechyné, 1969 e Cornubrotica Bechyné \& Bechyné, 1969; este último, até momento incluindo somente uma espécie, Cornubrotica dilaticornis (Baly, 1879) do Amazonas e Venezuela. Diferencia-se de Anisobrotica pelas tíbias anteriores e intermediárias nos machos com a face externa emarginada antes da extremidade e pelos antenômeros X e XI mais delgados que os precedentes (BeChyné \& BeChyné 1969).

O gênero Zischkaita Bechyné, 1956 incluía seis espécies neotropicais; mais recentemente, Moura (2003) acrescentou dois táxons: uma nova espécie, Zischkaita serrana, dos Campos de Cima da Serra, região serrana do Rio Grande do Sul e outra, $Z$. bucki, descrita originalmente no gênero Synbrotica por BECHYNÉ \& BECHYNÉ (1962).

Monocesta circumcincta foi descrita sucintamente por CLARK (1865) com base em exemplar do Brasil, sem definição da localidade; posteriormente, Bechyné \& BeChyné (1969) incluíram a espécie no gênero Caraguata Bechyné, 1954, citando apenas as localidades em que foram coletadas e uma pequena observação sobre o tamanho corporal e a coloração dos élitros.

Nesta contribuição objetiva-se descrever dois novos táxons de crisomelídeos neotropicais e recaracterizar Caraguata circumcincta (Clark, 1865) acrescentando caracteres morfológicos não abordados até o momento, além de fornecer ilustrações inéditas da espécie.

\section{MATERIAL E MÉTODOS}

O material estudado está depositado nas coleções entomológicas do Museu de Ciências Naturais, Fundação Zoobotânica do Rio Grande do Sul, Porto Alegre, Rio Grande do Sul (MCNZ) e do Instituto Nacional de Pesquisas da Amazônia, Manaus, Amazonas (INPA). A nomenclatura das estruturas de genitália segue Moura (1998c). As dimensões são fornecidas em milímetros.

\section{RESULTADOS}

\section{Luperina}

\section{Cornubrotica iuba sp. nov.}

Figs $1-5$

Etimologia. O epíteto, do tupi iuba= amarelo, refere-se à coloração do pronoto e dos élitros.

Macho. Cabeça preta, com pequena mancha no vértice e fronte marrons; área abaixo dos olhos até a base das mandíbulas amarelada; tegumento do vértice liso, brilhante e glabro. Olhos globosos, algo projetados, com maior diâmetro aproximadamente 3,5 vezes o comprimento da gena; próximo à margem superior interna, pêlo longo acompanhado de pequenos pêlos esparsos, quase imperceptíveis. Tubérculos anteníferos pouco desenvolvidos, brilhantes, separados entre si por uma sutura marcada. Fronte levemente convexa, com tegumento subopaco e pêlos esparsamente distribuídos. Clípeo curto, com pêlos longos e esparsos; labro encobrindo totalmente as man- 


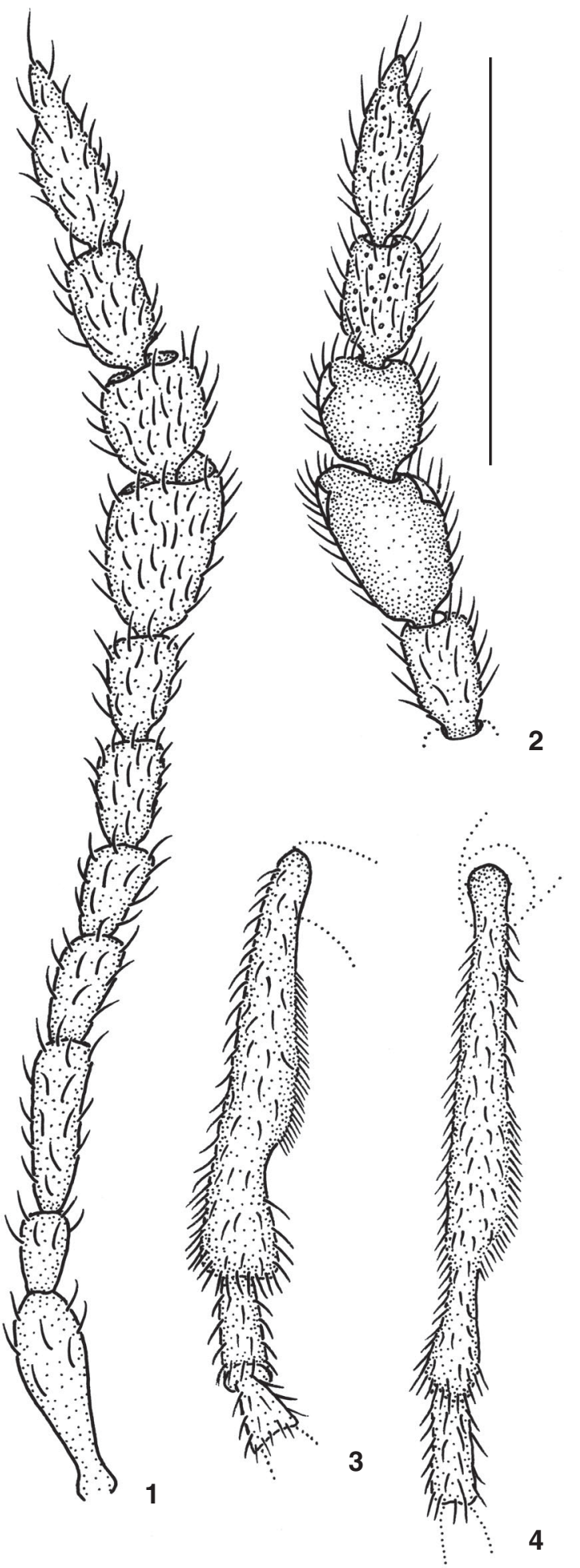

Figuras 1-4. Cornubrotica iuba sp. nov., holótipo macho: (1) antena, dorsal; (2) antenômeros VII-XI, ventral; tíbia anterior: (3) vista lateral interna; (4) vista frontal. Escala $=1 \mathrm{~mm}$. díbulas, emarginado na borda apical, brilhante e com fileira de pêlos alongados disposta transversalmente.

Antenas não atingem a metade dos élitros, marrons, exceto escapo amarelo. Pubescência nos artículos I e II escassa, esparsa, torna-se mais densa a partir do III, salvo ventralmente nos antenômeros VIII e IX, que são glabros (Fig. 2). Escapo subcilíndrico, com aproximadamente duas vezes o comprimento do pedicelo; antenômero III a VII subcilíndricos, o III cerca de 1,6 vez o comprimento do IV, IV com tamanho subigual aos três antenômeros seguintes; VIII e IX (Figs 1 e 2) alargados e ventralmente escavados; antenômeros X e XI subcilíndricos, não alargados.

Protórax amarelo, brilhante, com pontuação esparsa e pouco marcada; pronoto aproximadamente 1,7 vez mais largo que longo, com depressão transversal centro-posterior subarqueada, pouco profunda; lados arredondados, marginados, cada um dos ângulos portando um pêlo longo; mesosterno amarelo e metasterno marrom. Escutelo marrom, brilhante.

Élitros amarelos, com largura umeral cerca de 1,3 vez a largura da base do pronoto; pontuação densa e marcada uniforme em toda a extensão, exceto na extremidade, onde tornase mais irregular; pêlos eretos esparsamente distribuídos, inclusive nas margens.

Fêmures amarelos, tíbias e tarsos marrons; pubescência curta e esparsa, mais densa na metade posterior. Tíbias anteriores (Figs 3 e 4) e intermediárias com emarginações pré-apicais interna e externa, cada uma constituída de uma área deprimida e glabra.

Abdome marrom-claro, com pêlos esparsamente distribuídos.

Fêmea (Fig. 5). Cabeça preta; olhos com o maior diâmetro cerca de duas vezes o comprimento da gena. Antenas filiformes, com os artículos subcilíndricos, sem espessamentos (Fig. 5); antenômeros I a VII e extremidade do XI, marrons; VII e IX levemente mais escuros que a face ventral do escapo e dos antenômeros X e XI, que são amarelos.

Pernas anteriores e intermediárias sem emarginações préapicais nas faces interna e externa.

Dimensões, respectivamente macho e fêmea. Comprimento total 5,1-5,3; comprimento do élitro 3,9-4,2; largura umeral 2,0-2,1.

Material-tipo. Brasil, Bahia: Itabuna, holótipo macho, 11.IX.1968, P. Silva leg. (MCNZ 231909); parátipo fêmea, mesmos dados do holótipo (MCNZ 231910).

Discussão taxonômica. Cornubrotica iuba sp. nov. difere da outra espécie do gênero, C. dilaticornis (Baly, 1879), principalmente por apresentar élitros e fêmures uniformemente amarelados, escutelo e abdome marrons; em C. dilaticornis, os élitros são verde-azulados com o limbo externo amarelo, pernas castanho-escuras, escutelo preto e abdome preto com reflexo azulado. Além disso, o novo táxon parece estar relacionado com a Mata Atlântica, enquanto que a espécie-tipo do gênero possui distribuição amazônica (Brasil: Amapá, Amazonas e Pará; Venezuela: Bolívar). 


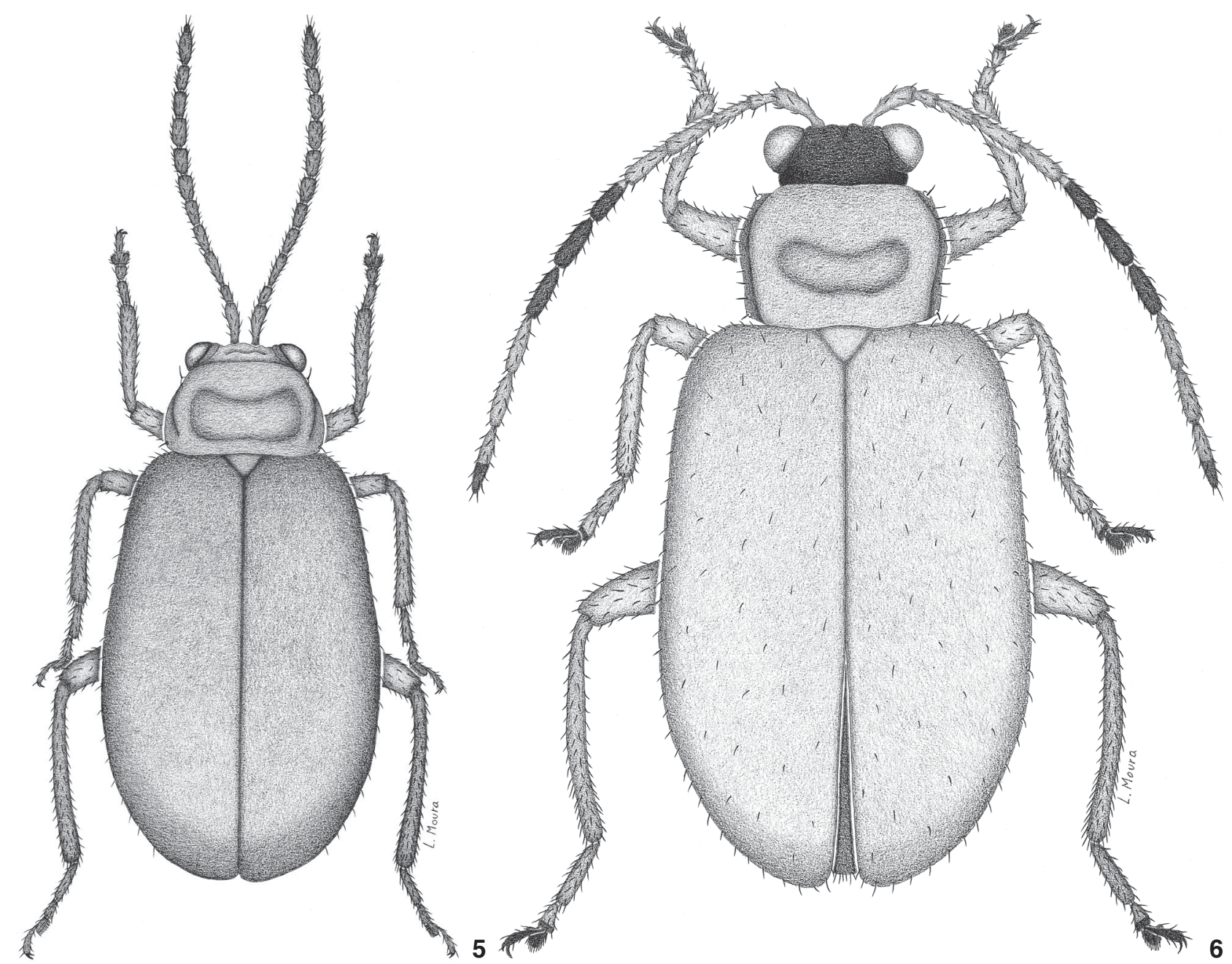

Figuras 5-6. (5) Cornubrotica iuba sp. nov., parátipo fêmea, 5,3 mm; (6) Zischkaita caapura sp. nov., holótipo fêmea, 5,6 mm.

\section{Zischkaita caapura sp. nov.}

Fig. 6

Etimologia. Do tupi caápúra $=$ morador do mato, alusivo à Floresta Amazônica, habitat dos exemplares coletados.

Fêmea. Cabeça preta, região frontal e gena castanho-escura; tegumento do vértice liso, brilhante e glabro. Olhos globosos e projetados (Fig. 6), com pêlos esparsos de diferentes tamanhos na margem. Tubérculos anteníferos desenvolvidos, brilhantes e separados entre si por uma sutura marcada. Fronte com superfície irregular, exceto uma formação transversal levemente convexa lisa, algo brilhante, que se origina nos tubérculos anteníferos e se estende até a borda clipeal. Clípeo curto, com pêlos longos voltados ventralmente; labro brilhante, castanho-escuro, deixando exposta somente a base lateral das mandíbulas, com as margens laterais arredondadas e a apical emarginada no centro.

Antenas (Fig. 6) atingem aproximadamente a metade dos élitros, amarelas, exceto antenômeros VI (salvo a base) a VIII e ápice do XI, castanho-escuros (em um dos exemplares, um anel largo no antenômero V). Pubescência no escapo e pedicelo curta e esparsa, mais densa nos antenômeros seguintes. Escapo subcilíndrico, com comprimento subigual à soma dos antenômeros II e III; pedicelo menor que o antenômero III, que por sua vez é mais curto que o IV; V-X subiguais, aproximadamente 0,7 vez o comprimento do XI, o mais longo de todos.

Protórax amarelo, brilhante, com uma depressão semicircular na metade posterior (Fig. 6); pontuação esparsa e pouco marcada restrita às áreas laterais. Lados arredondados, marginados, com pêlos curtos espaçados na borda e cada um dos ângulos um pêlo longo; pronoto aproximadamente 1,4 vez mais largo que longo, com maior largura no nível da linha mediana; mesosterno amarelo e metasterno marrom-claro; metepisterno densamennte revestido por pubescência branca. Escutelo amarelo, brilhante. 
Élitros (Fig. 6) brilhantes, amarelos; pontuação irregularmente marcada, mais concentrada no disco e na região lateral mediana; pêlos eretos esparsamente distribuídos no disco e na margem externa. Largura umeral aproximadamente 1,5 vez a largura da base do pronoto.

Pernas amarelas, exceto ápice do tarsômero II ao V (em um exemplar, a partir do III) castanho, pubescência curta e uniforme, mais densa nas tíbias e tarsos.

Abdome amarelo, algo brilhante, com pêlos uniformemente distribuídos.

Dimensões, fêmea. Comprimento total 5,6-5,7; comprimento do élitro 4,2-4,4; largura umeral 2,2-2,4.

Material-tipo. BRASIL, Amazonas: $60 \mathrm{Km} \mathrm{N}$ [orte] Manaus (Fazenda Esteio, ZF-3 Km 23), holótipo fêmea, 14.V.1985, B.C. Klein leg. (armadilha Malaise) (INPA); 2 parátipos fêmea, mesmos dados do holótipo, 10.IV.1985, 29.V.1985 (INPA, MCNZ 232962).

Discussão taxonômica. Zischkaita caapura sp. nov., juntamente com Z. bucki (Bechyné \& Bechyné, 1965) e Z. serrana (Moura, 2003), são as espécies do gênero que possuem élitros sem manchas; embora não se possa comprovar a existência de dimorfismo sexual verificados em $Z$. bucki e $Z$. serrana por termos somente exemplares fêmeas, $Z$. caapura sp. nov. distinguese por apresentar os élitros, pernas e abdome totalmente amarelos e antenas amarelas com os antenômeros VI a VIII e ápice do XI, castanho-escuros. Nas outras espécies, as antenas são castanho-escuras a pretas, pernas bicolores e abdome preto. Além das diferenças na coloração, $Z$. bucki e $Z$. serrana possuem distribuição geográfica, até o momento, restrita à Mata de Araucária, enquanto que a distribuição de $Z$. caapura sp. nov. é amazônica.

\section{Galerucina Caraguata circumcincta (Clark, 1865) Figs 7-18}

Monocesta circumcincta Clark, 1865: 316; Blackwelder, 1946: 686 (cat.); Bechyné, 1956: 288.

Caraguata circumcincta; Bechyné \& Bechyné, 1962: 8; 1969: 22; Wilcox, 1971: 25 (cat.).

Macho (Figs 7, 9-11, 13-15, 18). Cabeça amarela, com tegumento do vértice liso, brilhante e glabro; olhos globosos, com pêlos esparsos próximos à margem interna. Tubérculos anteníferos desenvolvidos, em conjunto com forma de um triângulo invertido e separados entre si por uma sutura marcada que se origina no vértice. Fronte com tegumento levemente pontuado, fosco e glabro. Clípeo brilhante, com pêlos esparsamente distribuídos. Labro cobrindo parcialmente as mandíbulas, brilhante, mais largo que longo, com as bordas laterais arredondadas e a apical emarginada.; fileira de pêlos alongados disposta transversalmente.

Antenas quase atingem a metade do comprimento dos élitros (Fig. 18), pretas, exceto base e face externa do escapo e área basal dos antenômeros II a IV amarelas. Tegumento dos

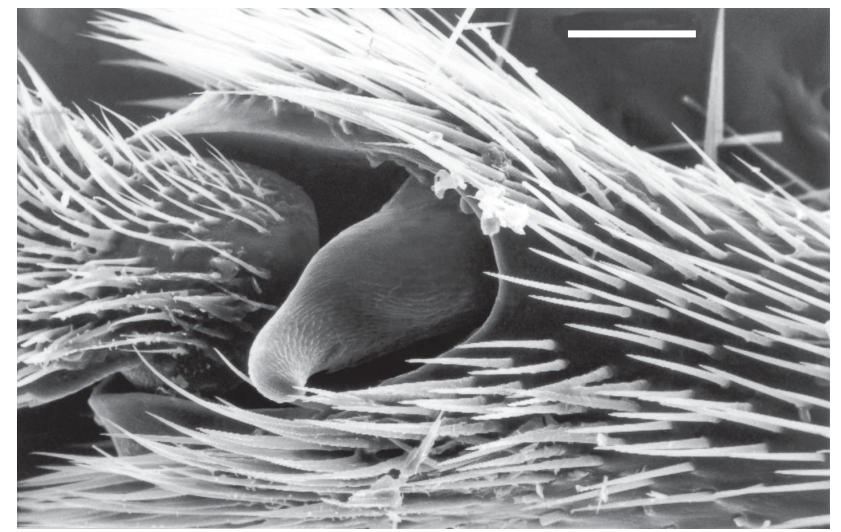

Figura 7. Caraguata circumcincta, macho, espinho apical da tíbia intermediária. Escala $=100 \mu \mathrm{m}$.

dois primeiros antenômeros brilhantes, com pêlos escassos; nos antenômeros seguintes, o tegumento é coberto por pubescência curta e densa. Escapo subcilíndrico, comprimento subigual à soma dos dois antenômeros seguintes; antenômero II mais curto que o III e este aproximadamente a metade do IV, que é o mais longo de todos; V a XI subiguais em forma e comprimento, exceto antenômero VII, que possui uma pequena protuberância apical externamente (Fig. 10).

Protórax amarelo, com tegumento liso e brilhante; pronoto subtrapezoidal, maior largura cerca de 2,5 vezes o comprimento, com uma depressão transversal mais profunda a cada lado do meio e uma outra menos marcada central, próxima à borda posterior, na região pré-escutelar; lados arredondados, convergentes para a porção anterior e cada um dos ângulos dotado de um pêlo longo (Fig. 18); mesosterno e metasterno amarelos, brilhantes e com pêlos esparsamente distribuídos. Escutelo preto, pubescente e densamente pontuado.

Élitros (Fig. 18) subovais, pretos (em alguns exemplares com tonalidade azul-esverdeada escura), com estreita faixa marginal amarela que se estende da região umeral até o ápice; superfície com pontuação densa e marcada, pubescência densa e uniforme constituída por pêlos curtos decumbentes entremeada com pêlos eretos esparsos. Largura umeral cerca de 1,3 vez a largura da base do pronoto.

Fêmures amarelos, lisos e brilhantes, com pêlos esparsamente distribuídos; tíbias anteriores pretas, com a face interna amarela (exceto na região apical). Pernas intermediárias: trocanteres (Fig. 9) projetados e aguçados posteriormente; tíbias pretas com a face ventral marrom-escura, armada de espinho disforme na extremidade apical ventral (Fig. 7). Pernas posteriores: trocanteres projetados e aguçados posteriormente; tíbias pretas com pequena área marrom-escura na região basal interna. Tarsos pretos em todas as pernas.

Abdome amarelo, brilhante, com pilosidade curta uniforme; urosternito V (Fig. 11) com uma emarginação central semicircular profunda na borda apical.

Revista Brasileira de Zoologia 22 (4): 1109-1115, dezembro 2005 


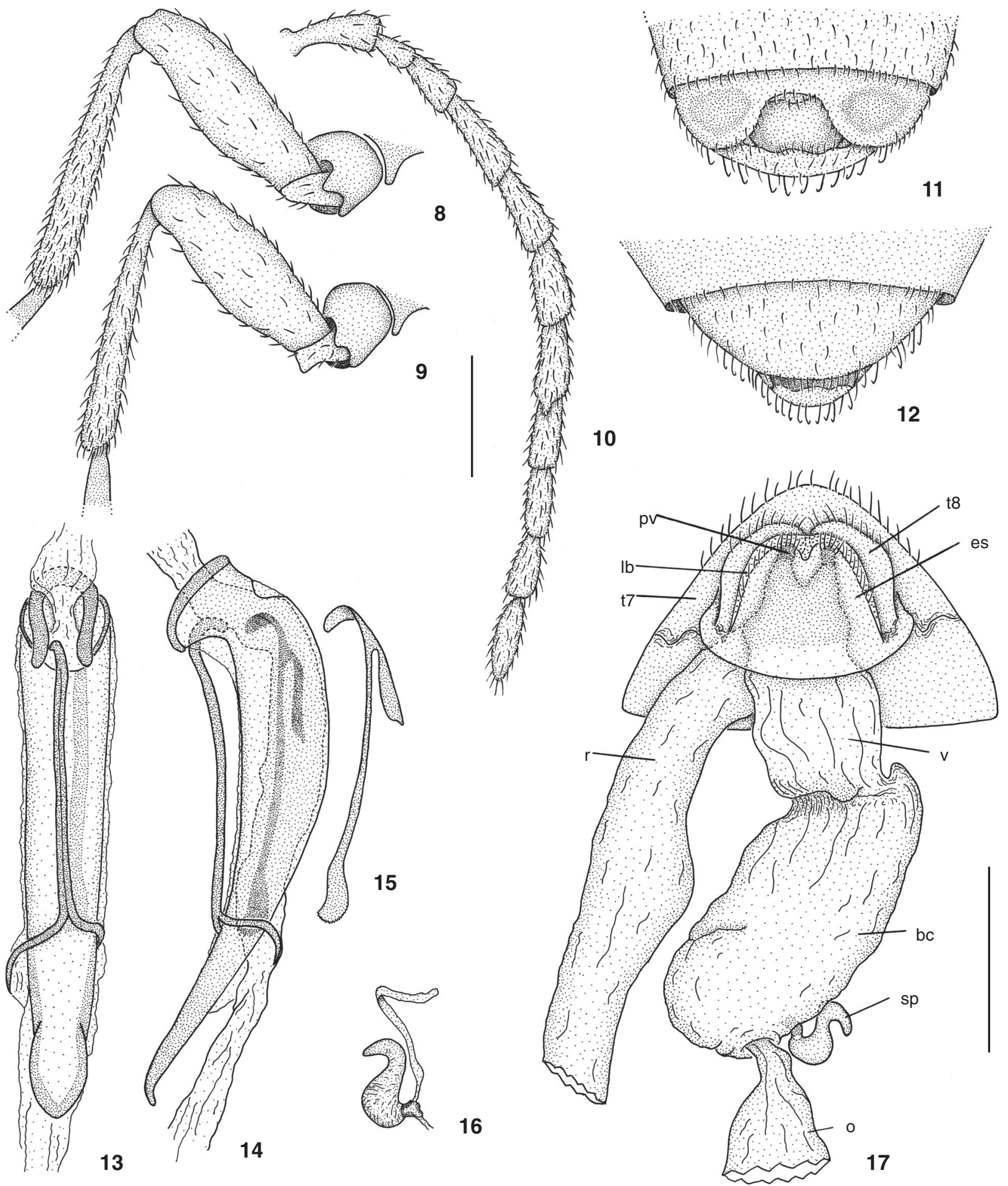

Figuras 8-17. Caraguata circumcincta: (8-9) pernas intermediárias: (8) fêmea, (9) macho; (10) antena, macho; (11-12) urosternito V: (11) macho, (12) fêmea; (13-15) macho: (13) aedeagus ventral, (14) aedeagus lateral; (15) flagellum; (16-17) fêmea: (16) espermateca; (17) conjunto da genitália. (bc) Bursa copulatrix, (es) esternito VIII, (lb) lobo membranoso, (o) oviduto, (pv) palpo vaginal, (r) reto, (sp) espermateca, (t7) tergito VII, (t8) tergito VIII, (v) vagina. Escalas: figuras 8-12, 13-17, respectivamente na mesma escala; Barra = 1 mm. 
Genitália (Figs 13-15). Aedeagus (Figs 13 e 14) com lobomédio alongado, esclerotizado, encurvado com a concavidade ventral, afilado para a extremidade e cerca de 1,6 vezes o comprimento do tégmen; ganchos da região basal fortemente esclerotizados, direcionados ventralmente e, quando observados dorsalmente, algo divergentes (Fig. 13). Tégmen hastiforme, com a extremidade anterior curvada e inserida no orifício-basal; braços-laterais com os ápices agudos e dirigidos para a extremidade do lobo-médio. Saco-interno com flagellum laminado, alongado, região basal dividida em dois ramos e a apical dilatada com a borda denteada (Fig. 15)

Fêmea (Figs 8, 12, 16 e 17). Pernas intermediárias (Fig. 8) e posteriores com os trocanteres não projetados e aguçados posteriormente; tíbias intermediárias sem espinho apical.

Genitália (Figs 16 e 17). Esternito VIII pouco esclerotinizado, subtrapezoidal, aproximadamente 0,45 vezes a maior largura do tergito VII, com borda apical dotada de pêlos e emarginada centralmente. Tergito VIII (Fig. 17) com os hemitergitos desenvolvidos, portando pêlos na margem apical. Ovipositor (segmento XI) com palpos vaginais digitiformes (Fig. 17), alargados na base, esclerotinizados apicalmente e pilosos na extremidade. Espermateca (Fig. 16) curvada; glândula espermatecal filiforme, levemente mais longa que a espermateca.

Dimensões, respectivamente macho/fêmea. Comprimento total, 8,1-8,9/8,3-10,2; comprimento do élitro, 6,4-7,1/6,78,4; largura umeral, 3,3-3,6/3,3-4,1.

Distribuição geográfica. Brasil (Pernambuco, Minas Gerais, Rio de Janeiro, São Paulo ao Rio Grande do Sul).

Material examinado. BRAsIL, Paraná: Curitiba (IAPAR), fêmea, 15.XII.1978; Santa Catarina: Rancho Queimado, fêmea, 12-15.I.1995, A. Bonaldo leg.; macho, 2 fêmeas, 15-18.XI.1995, L. Moura leg.; Rio Grande do Sul: Esmeralda, fêmea, 12.XII.1978, C.J. Becker leg.; Cambará do Sul, fêmea, 24.XI.1993, L. Moura leg.; fêmea, 24.XI.1993, A. Bonaldo leg.; 2 fêmeas, 24.XI.1993, E.H. Buckup leg.; fêmea, 25.XI.1993, A. Bonaldo leg.; macho, fêmea, 25.XI.1993, E.H. Buckup leg.; 2 machos, fêmea, 25.XI.1993, M.A.L. Marques leg.; fêmea, 25.XI.1993, L. Moura leg. macho, 14.XII.1993, V. Pitoni leg.; 3 machos, 2 fêmeas, 1921.XII.1994, L. Moura leg.; macho, fêmea, 19-21.XII.1994, A. Bonaldo leg.; 2 fêmeas, 19.XII.1994, M.H.M. Galileo leg.; macho, 20.XII.1994, M.H.M. Galileo leg.; Caxias do Sul (Fazenda Souza), macho, 19-20.XI.1999, L. Moura leg. (todos no MCNZ).

Discussão taxonômica. O dimorfismo sexual encontrado nas tíbias segue àquele encontrado nas espécies dos gêneros estudados por Moura (1998a,b,c) e LeSAGE (1986); no que tange à disposição dos espinhos apicais, os machos de Caraguata circumcincta possuem o espinho nas tíbias intermediárias, assim como Chlorolochmaea paralella (Bowditch, 1923) (Moura 1998a) e as espécies do gênero Ophraella (LeSage, 1986); as fêmeas são inermes. Em Iucetima, os espinhos estão presentes em todas as tíbias masculinas e Neolochmaea os apresenta nas pernas anteriores e intermediárias; nestes gêneros, as fêmeas também são destituídas de espinhos tibiais (Moura 1998b,c). Não foi verificado

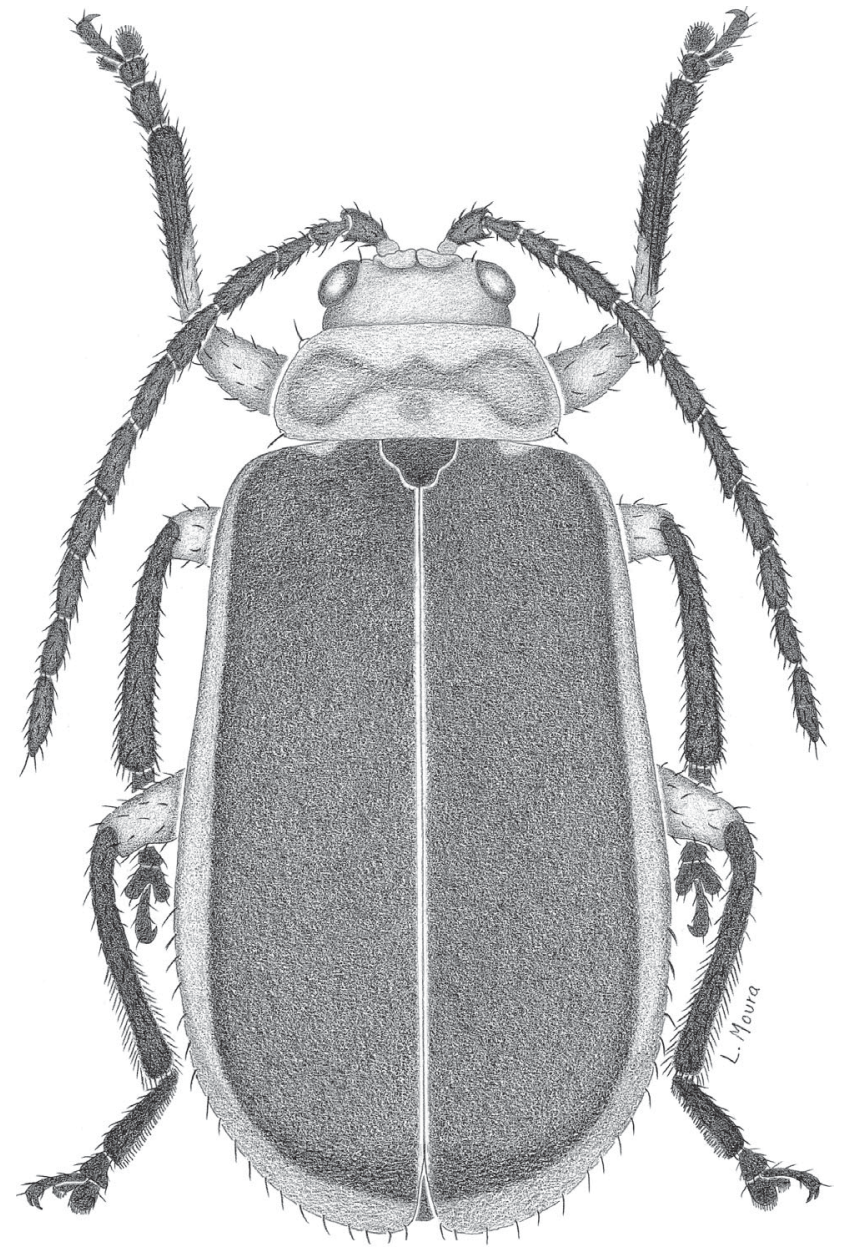

Figura 18. Caraguata circumcincta (Clark, 1865), macho, 8,5 mm.

dimorfismo sexual na extremidade dos élitros de C. circumcincta; nos gêneros Chlorolochmaea, Iucetima e Neolochmaea, os machos possuem a extremidade elitral arredondada e, nas fêmeas, os élitros são aguçados ou apresentam espinho sutural.

A genitália masculina e feminina de Caraguata circumcincta segue o padrão das espécies dos gêneros Chlorolochmaea, Iucetima e Neolochmaea (Moura 1998a,b,c). Caraguata circumcincta apresenta o aedeagus com flagellum no saco-interno, assim como Iucetima minor (Bechyné, 1954), I. acrocostata (Bechyné \& Bechyné, 1969) e Chlorolochmaea paralella (Bowditch, 1923), porém não possui o esclerito adicional disposto superiormente ao flagellum, encontrado nestas últimas espécies (Moura 1998a,b); em Neolochmaea o flagellum está ausente (Moura 1998c). No que se refere à genitália feminina, a única característica não observada na espécie estudada foi a ausência de apódema no esternito VIII, estrutura verificada em Chorolochmaea, Iucetima e Neolochmaea (Moura 1998a,b,c). 


\section{AGRADECIMENTOS}

A Célio Magalhães (INPA), pela obtenção de auxílio financeiro (CNPq) para ida à Manaus e pelo acesso à coleção entomológica.

\section{REFERÊNCIAS BIBLIOGRÁFICAS}

Bechyné, J. 1956. Reise des Herrn G. Frey in Südamerika: Galerucidae (Col. Phytophaga). Entomologische Arbeiten, Tutzing, 7 (1): 241-358.

Bechyné, J. \& B.S. DE Bechyné. 1962. Liste der bisher in Rio Grande do Sul gefundenen Galeruciden. Pesquisas Zoologia, São Leopoldo, 15: 5-68.

Bechyné, J. \& B.S. de Bechyné. 1969. Die Galerucidengattungen in Sudbrasilien. Iheringia, Série Zoologia, Porto Alegre, 36: 3-110.

Blackwelder, R.E. 1946. Checklist of the Coleopterous insects of Mexico, Central America the West Indies, and South America. Part 4. Bulletin of United States National Museum, Washington, 185: 551-763.

Clark, H. 1865. An examination of the Dejeanian Genus Coelomera (Coleoptera Phytophaga) and its affinities. The Annals and Magazine of Natural History, London, 16 (3): 315325.

LESAGE, L. 1986. A taxonomic monograph of the Nearctic galerucine genus Ophraella Wilcox (Coleoptera: Chrysomelidae). Memoirs of the Entomological Society of Canada, Ottawa, 133: 1-75.

Moura, L. DE A. 1998a. Novo status de Chlorolochmaea (Coleoptera, Chrysomelidae, Galerucinae, Galerucini). Iheringia, Série Zoologia, Porto Alegre, 84: 145-152.

Moura, L. DE A. 1998b. Iucetima, gênero novo de Galerucini da Região Neotropical (Coleoptera, Chrysomelidae, Galerucinae). Iheringia, Série Zoologia, Porto Alegre, 85: 77-88.

Moura, L. DE A. 1998c. Revisão do gênero Neolochmaea (Coleoptera, Chrysomelidae, Galerucinae, Galerucini). Iheringia, Série Zoologia, Porto Alegre, 85: 169-188.

MourA, L. DE A. 2003. Nova espécie de Zischkaita Bechyné e notas taxonômicas em Galerucini (Coleoptera, Chrysomelidae, Galerucinae). Revista Brasileira de Zoologia, Curitiba, 20 (4): 643-645.

WiLcox, J.A. 1971. Coleopterorum Catalogus. Chrysomelidae: Galerucinae. Gravenhage, W. Junk, vol. 78, $2^{\text {nd }}$ ed., p. 1220 .

Recebido em 10.V.2005; aceito em 16.XI.2005. 